\title{
Impaired Nuclear Responsiveness to Cytoplasmic Signals in Lymphocytes from Elderly Humans with Depressed Proliferative Responses
}

\author{
Janice K. Gutowski, * Judith B. Innes, $\ddagger$ Marc E. Weksler, $\ddagger$ and Stanley Cohen* \\ *Department of Pathology, University of Connecticut Health Center, Farmington, Connecticut 06032; and \\ $\ddagger$ Department of Medicine, Cornell University Medical Center, New York 10021
}

\begin{abstract}
Lymphocytes from many elderly individuals exhibit depressed proliferative responses to the plant phytohemagglutinin (PHA). We have previously reported that this proliferative defect is not due to a failure to generate a cytoplasmic activator of DNA replication (ADR). In the present study, we tested the DNA synthetic response of nuclei derived from aged cells to an exogenous source of ADR. We found that nuclei from aged lymphocytes exhibiting low PHA responses were impaired in their ability to synthesize DNA in response to ADR, compared with nuclei from younger adult donors. In contrast, those aged cells maintaining intact PHA responses provided nuclei that were also unimpaired in their response to ADR. The relationship between PHA responsiveness of the intact cells and ADR responsiveness of nuclei derived from these was a linear one. These results suggest that the depressed cellular reactivity of aged lymphocytes to PHA (when seen) may be due to a failure of these nuclei to respond to cytoplasmic stimulatory signals induced by the mitogen.
\end{abstract}

\section{Introduction}

Lymphocytes from many elderly humans and animals exhibit significantly impaired proliferative responses to the plant lectin phytohemagglutinin (PHA), ${ }^{1}$ as compared with lymphocytes from younger adults $(1,2)$. The decrease in tritiated thymidine incorporation by the aged cells is partly due to an increased sensitivity to chromosomal damage and cell cycle arrest induced by the radioisotope $(3,4)$. In addition, cells from aged donors show a true proliferative defect, characterized by a relative paucity of mitogen-responsive cells and the failure of these cells to expand into a pool of proliferating clones (4-6).

Although the mechanisms controlling cell growth in eukaryotic cells is still unclear, evidence suggests that cellular proliferation may be regulated by interactions between the nucleus and a factor or factors in the cytoplasm (reviewed in reference 7). For example, we have shown that spontaneously proliferating lymphoblastoid cells, PHA-stimulated human peripheral blood lymphocytes (PBL), and interleukin 2 (IL-2)-activated T cell blasts contain an extractable cytoplasmic protein called ADR

Received for publication 26 November 1985 and in revised form 13 February 1986

1. Abbreviations used in this paper: $\mathrm{ADR}$, extractable cytoplasmic protein; IL-2, interleukin 2; LPS, lipopolysaccharide; PHA, phytohemagglutinin; $\left[{ }^{3} \mathrm{H}\right] \mathrm{TTP}$, methyl-tritiated thymidine-5'-triphosphate.

J. Clin. Invest.

(c) The American Society for Clinical Investigation, Inc.

0021-9738/86/07/0040/04 \$1.00

Volume 78, July 1986, 40-43 that is capable of inducing DNA synthesis in isolated quiescent nuclei $(8,9)$. This factor is not released from the cell, has no effect on intact cells, and is not detectable in the cytoplasm of resting PBL (8). These findings suggest that ADR may serve as a cytoplasmic "second signal" for PHA- or IL-2-induced lymphoproliferation. The participation of cytoplasmic factors in the activation of lymphocyte nuclei has also been reported by Eda et al. (10), who demonstrated the restoration of lipopolysaccharide (LPS) responsiveness in $\mathrm{C} 3 \mathrm{H} / \mathrm{HeJ}$ mouse lymphocytes by microinjecting cytosol from LPS-stimulated cells of the responder strain $\mathrm{C} 3 \mathrm{H} / \mathrm{HeN}$.

In a previous study, we asked whether the impaired PHA response of aged humans was associated with a failure of these PBL to generate a cytoplasmic stimulatory factor. We found that cytoplasmic extracts prepared from lymphocytes from elderly humans induced as much DNA synthesis in isolated quiescent nuclei as extracts from the adult cells, even when the cellular PHA response of the aged PBL was significantly impaired (11). This result was somewhat unexpected in that, using PBL from young adult donors, we had always observed a close positive linear correlation between cellular proliferation and cytoplasmic $\operatorname{ADR}$ activity $(9,11)$. Our findings suggested that the proliferative defect in aged cells was not due to a failure to generate cytoplasmic stimulatory factors, but to an impaired nuclear response to these intracellular signals. The purpose of the present study was to test this possibility directly. For this purpose, we made a detailed study of the cellular PHA response and nuclear ADR response of five separate pairs of aged and adult donors. To see if there may be an association between these two activities, we specifically included aged individuals whose abilities to respond to PHA varied greatly. We found that PBL nuclei, isolated from aged lymphocytes with depressed proliferative responses, exhibit impaired DNA-synthetic responses to cytoplasmic signals as compared with PBL nuclei from adult cells.

\section{Methods}

\section{Materials}

Cell cultures. Peripheral blood was collected by venipuncture from healthy volunteers. The adult donors (aged 22-30 yr) included laboratory personnel and medical students. The elderly donors (aged 66-72 yr) were ambulatory and in good health and were not taking any medications known to affect lymphocyte functions. PBL were obtained by FicollHypaque density gradient centrifugation as per Hefton et al. (4). The cells were cultured in triplicate wells of a microtiter plate in RPMI 1640 (M.A. Bioproducts, Walkersville, MD), 10\% human AB serum, $100 \mathrm{U}$ penicillin/ml, $100 \mu \mathrm{g}$ streptomycin/ml, and $2 \mathrm{mM}$ L-glutamine (Gibco, Grand Island, NY) at $10^{6}$ lymphocytes $/ \mathrm{ml}$ in the presence and absence of $10 \mu \mathrm{g} / \mathrm{ml}$ of PHA (Sigma Chemical Co., St. Louis, MO, and BurroughsWellcome Co., Research Triangle Park, NC) for $\sim 66 \mathrm{~h}$. The wells were pulsed with $1 \mu \mathrm{Ci}\left[{ }^{3} \mathrm{H}\right] \mathrm{TdR}(6.7 \mathrm{Ci} / \mathrm{mmol}$, New England Nuclear, Boston, MA) for $8 \mathrm{~h}$. The cultures were harvested onto glass fiber filter paper (Reeve-Angel; Whatman Laboratory Products Inc., Clifton, NJ) using a 
multi-well automated sample harvester (Cambridge Technology, Cambridge, MA). The glass fiber disks were placed in polyethylene minivials (VWR Scientific, Boston, MA) with $4 \mathrm{ml}$ scintillation cocktail (Aquasol; New England Nuclear) and counted in a liquid scintillation counter.

Preparation of isolated nuclei. Isolated nuclei were prepared from the adult and aged PBL by the detergent lysis procedure of Benz and Strominger (12). Nuclei were adjusted to $2 \times 10^{7} / \mathrm{ml}$ in $0.25 \mathrm{M}$ sucrose/ $5 \mathrm{mM} \mathrm{CaCl}_{2} / 25 \mathrm{mM}$ Hepes, $\mathrm{pH} 8 / 2 \%$ dextran and used immediately. These preparations were not contaminated by intact cells or as determined by visual examination (phase contrast and electron microscopy). In any event, ADR has no effect on intact cells (8), so that even if intact cells remained in the nuclear preparations, they could not have influenced the results.

Preparation of cytoplasmic extracts. The T lymphoblastoid cell line MOLT 4 was used as a standardized source of ADR. Extracts were prepared by hypotonic lysis and Dounce homogenization, as previously described (8).

Assay for DNA synthesis in isolated nuclei. The assay used was a modification of the procedure of Das (13). Assays were performed in triplicate in 96-well microtiter plates. Nuclei $\left(20 \mu \mathrm{l}, 4 \times 10^{5}\right)$ were cultured with $40 \mu$ l reaction buffer $(0.25 \mathrm{M}$ sucrose/ $25 \mathrm{mM}$ Hepes, $\mathrm{pH} 7.8 / 2 \%$ dextran) and $40 \mu \mathrm{l}$ MOLT 4 extract. In some wells, extract and nuclei were cultured with reaction buffer alone (60 and $80 \mu \mathrm{l}$, respectively). 50 $\mu \mathrm{l}$ of incorporation mixture, containing $0.5 \mathrm{mM}$ each $2^{\prime}$-deoxyadenosine 5 -triphosphate, 2'-deoxyguanosine 5'-triphosphate, and 2'-deoxycytidine $5^{\prime}$-triphosphate, $5 \mathrm{mM}$ adenosine 5 -triphosphate, $12.5 \mathrm{mM}$ phosphoenolpyruvate, $10 \mathrm{U}$ pyruvate kinase/ml, $38 \mathrm{mM}$ Hepes (pH 7.8), 100 $\mathrm{mM} \mathrm{KCl}, 125 \mathrm{mM}$ sucrose, $12.5 \mathrm{mM} \mathrm{MgCl}_{2}$, and $2 \mathrm{mM}$ dithiothreitol, were added to each well. Each well then received $3 \mu l$ methyl-tritiated thymidine-5'-triphosphate $\left(\left[{ }^{3} \mathrm{H}\right] \mathrm{TTP}, 0.5 \mathrm{mCi} / \mathrm{ml}, 50-80 \mathrm{Ci} / \mathrm{mM}\right.$, New England Nuclear). The plates were incubated at $37^{\circ} \mathrm{C}$ for $3 \mathrm{~h}$. These conditions had been shown to result in maximal $\left[{ }^{3} \mathrm{H}\right]$ TTP incorporation. Time zero measurements were also performed to measure nonspecific background radioactivity. These values were substracted from the respective postincubation counts. At the end of the incubation period, the reactions were stopped by the addition of $10 \mu l 1.35 \mathrm{M} \mathrm{NaOH}$ to each well. After a 5 -min incubation at $0^{\circ} \mathrm{C}$, DNA was precipitated by the addition of $150 \mu \mathrm{l} 9.5 \%$ trichloroacetic acid/1\% sodium pyrophosphate to each well. After a 15 -min incubation at $0^{\circ} \mathrm{C}$, the cultures were harvested as described above. The evidence that this assay measures DNA replication has been summarized (14), and includes the absolute requirement for ATP and the presence of replicative forks and "eyes." In addition,
DNA synthesis may be shown to be discontinuous in this assay, with nascent $4 \mathrm{~S}$ fragments chased into fast-sedimenting DNA in pulse-labeling experiments (15).

\section{Results}

Isolated nuclei were prepared from lymphocytes from aged (66$72 \mathrm{yr})$ or control adult (22-35 yr) donors, and tested for the ability to synthesize DNA in response to ADR extracted from proliferating MOLT 4 cells. In addition, samples of the intact aged and adult cells were cultured with PHA to monitor their proliferative responses. Results from five such experiments are presented in Table I. As shown in exps. 1-3, PBL from most of the aged donors showed significantly impaired PHA responses (top half of table). Nuclei isolated from these PBL showed similarly depressed responses to ADR (bottom half of table). Occasionally, we encountered aged donors whose PBL showed intact PHA responses. Interestingly, the nuclei isolated from these cells showed correspondingly unimpaired responses to ADR (Table I, exps. 4 and 5). These results suggested a relationship between the level of nuclear impairment and the severity of the proliferative defect of the intact aged cells. To directly examine this point, we plotted the PHA responsiveness of the intact aged PBL against the responsiveness of their nuclei to ADR (both parameters measured as a percentage of adult control responses). As shown in Fig. 1, there was a strict linear relationship between these two activities (correlation coefficient $=0.99$ ). Note that the decreased responses of nuclei from the aged donors was not due to a difference in the ADR dose-response relationship or kinetics of the ADR response. As shown in Fig. 2, there was no difference in the dose-response curves for the ADR response of aged or adult nuclei at any of the time points tested.

\section{Discussion}

The impaired PHA response of lymphocytes from some elderly individuals has been described previously by several laboratories and is well documented (1-6). The purpose of this study was to

Table I. ADR Responsiveness of Isolated Nuclei Derived from PBL from Aged and Adult Donors

\begin{tabular}{|c|c|c|c|c|c|}
\hline \multirow[b]{2}{*}{ Culture } & \multicolumn{5}{|c|}{${ }^{3} \mathrm{H}$-Incorporation ( $\overline{\mathrm{x}} \mathrm{cpm}$ per culture $\pm \mathrm{SD}$ ) } \\
\hline & Exp. 1 & Exp. 2 & Exp. 3 & Exp. 4 & Exp. 5 \\
\hline Adult PBL + media & $703 \pm 30$ & $469 \pm 31$ & $300 \pm 64$ & $1,768 \pm 850$ & $208 \pm 29$ \\
\hline Aged PBL + media & $331 \pm 30$ & $389 \pm 34$ & $548 \pm 52$ & $412 \pm 49$ & $430 \pm 24$ \\
\hline Adult PBL + PHA & $112,226 \pm 11,805$ & $114,706 \pm 18,309$ & $100,072 \pm 3,268$ & $128,176 \pm 1,968$ & $65,276 \pm 7,333$ \\
\hline Aged PBL + PHA & $59,137 \pm 4,586$ & $41,760 \pm 1,243$ & $59,366 \pm 3,470$ & $149,234 \pm 9,382$ & $59,131 \pm 10,848$ \\
\hline Adult nuc alone & $3,815 \pm 462$ & $2,240 \pm 239$ & $6,144 \pm 1,154$ & $2,358 \pm 91$ & $550 \pm 299$ \\
\hline Aged nuc alone & $2,382 \pm 485$ & $1,778 \pm 234$ & $2,171 \pm 97$ & $2,188 \pm 120$ & $658 \pm 86$ \\
\hline M4 ext alone & $5,292 \pm 281$ & $3,781 \pm 376$ & $657 \pm 65$ & $3,267 \pm 508$ & $200 \pm 80$ \\
\hline Adult nuc + M4 ext & $93,814 \pm 920$ & $31,941 \pm 396$ & $36,912 \pm 6,867$ & $24,551 \pm 591$ & $5,765 \pm 211$ \\
\hline Aged nuc + M4 ext & $53,997 \pm 1,213$ & $13,148 \pm 978$ & $21,081 \pm 2,064$ & $28,252 \pm 1,759$ & $5,028 \pm 643$ \\
\hline
\end{tabular}

PBL were obtained by Ficoll-Hypaque density gradient centrifugation, as per Hefton et al. (4). Before preparing nuclei, $\sim 2 \times 10^{5}$ PBL were removed and cultured in the presence and absence of $10 \mu \mathrm{g} / \mathrm{ml}$ PHA (Sigma Chemical Co.) for $3 \mathrm{~d}$, as described in the Methods section. During the last $8 \mathrm{~h}$, each culture was pulsed with $1 \mu \mathrm{Ci}\left[{ }^{3} \mathrm{H}\right] \mathrm{TdR}$ and harvested as described. Isolated nuclei were prepared from aged and adult PBL as described previously $(8,9) .4 \times 10^{5}$ nuclei (nuc) were cultured with and without the standardized source of ADR (40 $\mu 1$ cytoplasmic extract prepared from proliferating MOLT 4 cells [M4 ext]), as described in the Methods section. Each well received $3 \mu \mathrm{Ci}\left[{ }^{3} \mathrm{H}\right] \mathrm{TTP}$. The plates were incubated for $3 \mathrm{~h}$ at $37^{\circ} \mathrm{C}$. Background $\left[{ }^{3} \mathrm{H}\right] \mathrm{TTP}$ incorporated at time zero incubations have been subtracted. Each experiment represents an individual pair of aged and adult donors. 


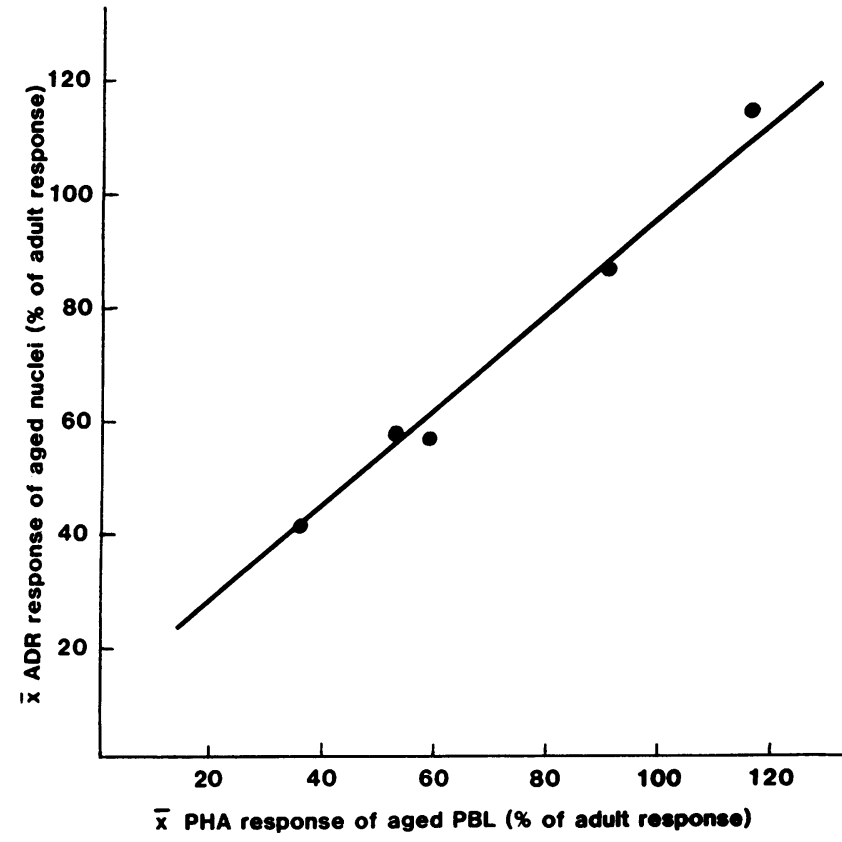

Figure 1. Correlation between cellular PHA response and nuclear ADR response in intact PBL and isolated nuclei, respectively, from aged donors. The curve was derived from data presented in Table I. The regression line was obtained by plotting percent of young adult PHA response versus percent of young adult nuclear response obtained in the five experiments $\left(r^{2}=0.99\right)$.

investigate whether the depressed cellular response of aged cells, when seen, may be associated with a depressed nuclear response to cytoplasmic signals which have been shown to be generated by the extracellular mitogen $(8,11)$. We found that nuclei derived from poorly responsive aged lymphocytes were indeed impaired in their ability to synthesize DNA in response to cytoplasmic stimulatory factors, compared to nuclei from younger adult donors. Those aged cells exhibiting intact PHA responses provided nuclei that were also unimpaired in their response to ADR. Although results from only five pairs of old and young subjects are presented, the close tracking of nuclear ADR reactivity with cellular proliferative capacity, in conjunction with our previous demonstration of normal to elevated ADR levels in aged cells, strongly suggests that the depressed PHA response seen in lymphocytes from some aged humans is due to a loss of responsiveness of their nuclei to cytoplasmic signals induced by the mitogen.

It is likely that individuals of even greater age than those studied would have shown greater proliferative defects. However, the clinical material available for this study was sufficient to provide a range of responsiveness from normal levels to $\sim 35 \%$ of that of cells from young adult controls. Because of the necessity of using well-followed, healthy, ambulatory, drug-free individuals, we only had access to a very small number of patients at the time of study. However, the results obtained were highly significant, and the association of nuclear and proliferative responsiveness (Fig. 1) had a correlation coefficient of 0.99 . This diminished nuclear reactivity was observed over a range of doses of ADR and times of incubation (Fig. 2). Moreover, our previous finding of normal ADR levels in another group of elderly subjects (11) is consistent with the conclusion presented here; namely, that the locus of the proliferative defect is nuclear. It is, of course,

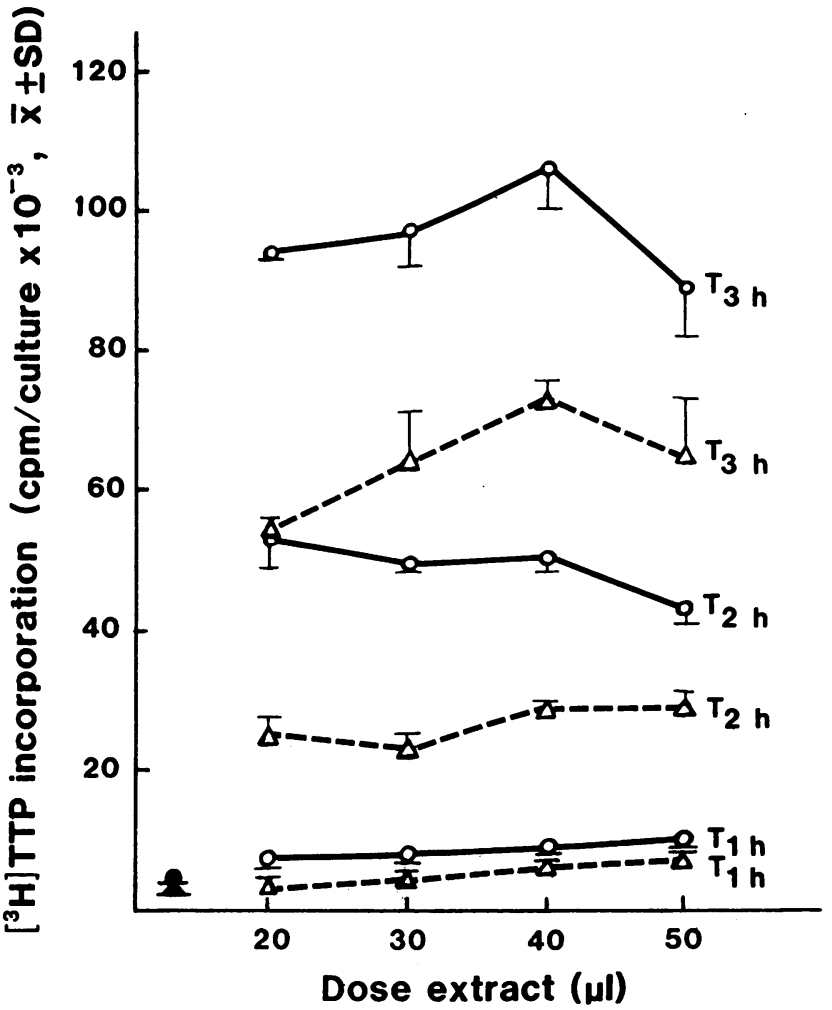

Figure 2. Induction of DNA synthesis in nuclei from aged and adult PBL by cytoplasmic extracts from MOLT 4 cells: dose-response and kinetics. Nuclei were prepared from aged and adult PBL as described previously (12). $4 \times 10^{5}$ adult (--- $\left.0--\cdot\right)$ or aged (--- $\left.\Delta-\cdot-\right)$ nuclei were cultured for 1-3 h with 20-50 $\mu$ l MOLT 4 extract, as described in the Methods section. The cpm incorporated by the extracts alone were $10 \%$ or less of the $\mathrm{cpm}$ incorporated by nuclei plus extract. The cpm incorporated by adult $(\bullet)$ or aged $(\Delta)$ nuclei alone are depicted on the graph. Data represent results from a representative experiment.

possible that when a larger population is available for study, an additional cytoplasmic loci for this defect will emerge in some cases. However, we have not observed this in either the present or the previous study.

The hypothesis that age-related changes in cellular proliferative capacity are due to changes in the nuclear compartment of the cell is supported by results from a number of studies (1317). For example, Hayflick and Moorhead observed that human embryonic fibroblasts will divide spontaneously in culture $\sim 50$ times and then die, a phenomenon that has been interpreted as aging at the cellular level (16). Interestingly, there appears to be an inverse relationship between the division potential of cultured fibroblasts and the age of the cell donor (17). Wright and Hayflick (18) and Muggleton-Harris and Hayflick (19) fused whole cells, cytoplasts (enucleated cells), and karyoplasts (nuclei) in various stages of their lifespan and found that the mechanism controlling the proliferative potential of a cell may be located in the nucleus. In other studies on in vitro aging, Collins and $\mathrm{Chu}$ found that DNA synthesis was reduced in proliferating cells of aging cultures at the level of the nuclear matrix, probably due to alterations in DNA structure (20).

The nuclear defect responsible for the diminished response of aged PBL nuclei to ADR is not yet known. Note, however, that a number of other age-related changes in the cell nucleus have been reported. For example, in the presence of tritiated 
thymidine, cells from aged donors show more chromosomal damage and cell cycle arrest than do cells from adult controls (3). In addition, DNA repair capacity has been shown to decrease with age (21-23). Furthermore, the frequency of aneuploidy increases with age (24), as does the frequency of chromosomal structural aberrations (25). The relationship, if any, between these effects and the impaired ability to synthesize DNA in response to cytoplasmic factors remains an open question. Studies in progress on the mechanism of the ADR effect itself may shed light on this issue.

Impaired nuclear responsiveness to cytoplasmic factors may not be involved in proliferative defects unrelated to aging. For example, Watanabe and Ohara have shown that nuclei from LPS-unresponsive $\mathrm{C} 3 \mathrm{H} / \mathrm{HeJ}$ mice could be activated by LPS after being transferred into cells from an LPS-responder strain (26). Furthermore, B cells from the $\mathrm{C} 3 \mathrm{H} / \mathrm{HeJ}$ mice became responsive to LPS after being microinjected with cytosol from LPS-stimulated responder cells (10). These results suggested that nuclei from $\mathrm{C} 3 \mathrm{H} / \mathrm{HeJ}$ mice are capable of intact LPS-induced DNA-synthetic responses if provided with the appropriate cytoplasmic stimulatory signals. Thus, the impaired proliferative response to exogenous mitogenic agents seen in human aging may be pathogenetically distinct from that seen in cases of genetic unresponsiveness.

Although a large variety of immunologic reactions have been shown to be impaired to some extent in the aged (27), it is likely that these changes are secondary to a more basic underlying defect or defects. Since all immunologic responses are ultimately dependent on proliferation and differentiation, the findings reported here may provide one unifying explanation for at least some of these diminished responses.

\section{Acknowledgments}

This work was supported by National Institutes of Health grants AI12477, AG-05704, CA-35703, AG-00239, and AG-00541.

\section{References}

1. Weksler, M. E., and T. H. Hütteroth. 1974. Impaired lymphocyte function in aged humans. J. Clin. Invest. 53:99-104.

2. Hori, Y., E. H. Perkins, and M. K. Halsall. 1973. Decline in phytohemagglutinin responsiveness of spleen cells from aging mice. Proc. Soc. Exp. Biol. Med. 144:48-52.

3. Staiano-Coico, L., Z. Darzynkiewicz, J. M. Hefton, R. Dutkowski, G. Darlington, and M. E. Weksler. 1983. Increased sensitivity of lymphocytes from people over 65 to cell cycle arrest and chromosomal damage. Science (Wash. DC). 219:1335-1337.

4. Hefton, J. M., G. J. Darlington, B. A. Casazza, and M. E. Weksler. 1980. Immunologic studies of aging. V. Impaired proliferation of PHA responsive human lymphocytes in culture. J. Immunol. 125:1007-1010.

5. Inkeles, B., J. B. Innes, M. M. Kuntz, A. S. Kadish, and M. E. Weksler. 1977. Immunological studies of aging. III. Cytokinetic basis for the impaired response of lymphocytes from aged humans to plant lectins. J. Exp. Med. 145:1176-1187.

6. Tice, R. R., E. L. Schneider, D. Kram, and P. Thorne. 1979. Cytokinetic analysis of the impaired proliferative response of peripheral lymphocytes from aged humans to phytohemagglutinin. J. Exp. Med. 149:1029-1041.
7. Ord, M. J. 1979. The separate roles of nucleus and cytoplasm in the synthesis of DNA. Int. Rev. Cytol. 9(Suppl.):221-277.

8. Gutowski, J. K., and S. Cohen. 1983. Induction of DNA synthesis in isolated nuclei by cytoplasmic factors from spontaneously proliferating and mitogen-activated lymphoid cells. Cell. Immunol. 75:300-311.

9. Gutowski, J. K., B. Mukherji, and S. Cohen. 1984. The role of cytoplasmic intermediates in IL 2-induced T cell growth. J. Immunol. 133:3068-3074.

10. Eda, Y., J. Ohara, and T. Watanabe. 1983. Restoration of LPS responsiveness of $\mathrm{C} 3 \mathrm{H} / \mathrm{HeJ}$ mouse lymphocytes by microinjection of cytoplasmic factor(s) from LPS-stimulated normal lymphocytes. J. Immunol. 131:1294-1299.

11. Gutowski, J. K., J. Innes, M. E. Weksler, and S. Cohen. 1984. Induction of DNA synthesis in isolated nuclei by cytoplasmic factors. II. Normal generation of cytoplasmic stimulatory factors by lymphocytes from aged humans with depressed proliferative responses. J. Immunol. 132:559-562.

12. Benz, W. C., and J. L. Strominger. 1975. Viral and cellular DNA synthesis in nuclei from human lymphocytes transformed by EpsteinBarr virus. Proc. Natl. Acad. Sci. USA. 72:2413-2417.

13. Das, M. 1980. Mitogenic hormone-induced intracellular message: assay and partial characterization of an activatory of DNA replication induced by epidermal growth factor. Proc. Natl. Acad. Sci. USA. 77: 112-116.

14. Cohen, S., and J. K. Gutowski. 1985. Intracytoplasmic signals for DNA replication in lymphocyte proliferation. In Mediators in Cell Growth and Differentiation. R. J. Ford and A. L. Maizel, editors. Raven Press, New York. 11-19.

15. Jazwinski, S. M., J. L. Wang, and G. M. Edelman. 1976. Initiation of replication in chromosomal DNA induced by extracts from proliferating cells. Proc. Natl. Acad. Sci. USA. 73:2231-2235.

16. Hayflick, L., and P. S. Moorhead. 1961. The serial cultivation of human diploid cell strains. Exp. Cell Res. 25:585-593.

17. Hayflick, L. 1965. The limited in vitro lifetime of human diploid cell strains. Exp. Cell Res. 37:614-636.

18. Wright, W. E., and L. Hayflick. 1975. Nuclear control of cellular aging demonstrated by hybridization of a nucleate and whole cultured normal human fibroblasts. Exp. Cell Res. 96:113-121.

19. Muggleton-Harris, A. L., and L. Hayflick. 1976. Cellular aging studied by the reconstruction of replicating cells from nuclei and cytoplasms isolated from normal human diploid cells. Exp. Cell Res. 103: 321-330.

20. Collins, J. M., and A. K. Chu. 1985. Reduction of DNA synthesis in aging but still proliferating cells. J. Cell. Physiol. 124:165-173.

21. Niedermüller, H., G. Hofecker, and A. Kment. 1980. Influence of age on DNA repair in vivo. In DNA Repair and Late Effects. $\mathrm{H}$. Altman, E. Riklis, and H. Slor, editors. Publ. NRCN, Israel. 15-26.

22. Niedermüller, H. 1982. Age-dependency on DNA repair in rats after DNA damage by carcinogens. Mech. Ageing Dev. 19:259-263.

23. Hart, R. W., and R. B. Setlow. 1976. DNA repair in late-passage human cells. Mech. Ageing Dev. 5:67-72.

24. Jacobs, P. A., W. M. Court Brown, and R. Doll. 1961. Distribution of human chromosome counts in relation to age. Nature (Lond.). 191: 1178-1180.

25. Preumont, A. M., P. Van Gansen, and J. Brachet. 1978. Cytochemical study of human lymphocytes stimulated by PHA as a function of donor age. Mech. Ageing Dev. 7:25-31.

26. Watanabe, T., and J. Ohara. 1981. Functional nuclei of LPSnon-responder $\mathrm{C} 3 \mathrm{H} / \mathrm{HeJ}$ mice after transfer into LPS-responder. Nature (Lond.). 290:58-59.

27. Makinodan, T., and M. M. B. Kay. 1980. Age influence on the immune system. Adv. Immunol. 29:287-330. 